\title{
Violência e agressividade: Diferenças a partir da linguagem e do inominável da feminilidade
}

\section{Violence and aggression: differences starting at the language and the unnameable femininity}

\section{Violencia y agresividad: Diferencias a partir del lenguaje y de lo innombrable de la femineidad}

\author{
Sérgio Laia* \\ Universidade Fundação Mineira de Educação e Cultura - FUMEC, Belo Horizonte, \\ Minas Gerais, Brasil
}

Heloisa Caldas**

Universidade do Estado do Rio de Janeiro - UERJ, Rio de Janeiro, Rio de Janeiro, Brasil

\begin{abstract}
RESUMO
Norteado por referenciais psicanalíticos, este artigo aborda a distinção entre agressividade e violência a partir dos limites da linguagem para se nomear o feminino. São discutidos aspectos da violência em seu estágio atual, tais como: sua escalada, seu deslocamento do espaço privado ao público, suas formas de manifestação nas famílias. Abordando mais especificamente a violência dirigida contra o feminino, investiga-se as condições que a propiciam assim como perspectivas de saída dos embates que ela implica. Um novo modo de abordar o feminino é configurado como uma saída, na medida em que se possa dar um passo adiante das políticas de empoderamento da mulher, mais assentadas na igualdade sexual, e que se possa lidar mais efetivamente com as disparidades subjetivas.
\end{abstract}

Palavras-chave: agressão, violência, feminino, linguagem.

\begin{abstract}
Guided by psychoanalytical references, this article discusses the distinction between aggression and violence starting at the language and its limits in naming the femininity. Among discussed aspects of the current violence stand its progressive increase, its displacement from the private to the public space, its forms of manifestation within families. In order to address more specifically the violence directed against women, an investigation is pursued on the conditions that engender it as well as the prospects of solutions to the conflicts that it entails. A new way to approach the feminine turns out to be a solution as long as a step forward can be taken in women's empowerment policies, more settled in sexual equality, and subjective disparities can be dealt more effectively.
\end{abstract}

Keywords: aggression, violence, feminine, language. 


\begin{abstract}
RESUMEN
Desde una lectura psicoanalítica, este artículo aborda la diferencia entre agresividad y violencia a partir del lenguaje y sus límites al nombrar lo femenino. Son discutidos aspectos de la violencia actual como su escalada, su desplazamiento del espacio privado al público, sus formas de manifestación en las familias y en las escuelas. Abordando más específicamente la violencia dirigida contra lo femenino, se estudian las condiciones que la promueven y también las perspectivas de salida de estos enfrentamientos, a partir del propio femenino, a medida que se pueda dar un paso adelante de las políticas de empoderamiento de la mujer, más asentadas en la igualdad sexual, y poder lidiar más eficazmente como las disparidades subjetivas.
\end{abstract}

Palabras clave: agresividad, violencia, femenino, lenguaje.

\title{
1 Introdução
}

A violência é mais assustadora e angustiante quando surge onde menos esperamos encontrá-la. Em um mundo como o nosso, caracterizado pela perda dos ideais, temos ainda expectativas de prevenção ou ainda encontramos propostas interessantes que procuram enfrentá-la e dar-lhe alguma solução, mas a angústia e o susto são mais intensos justamente quando a violência advém onde nos pareceria improvável que ela irrompesse, ganhando espaço nas páginas dos jornais, nas telas de televisão e dos computadores. Porém, se evocarmos histórias como as de Caim e Abel, Medeia, Hamlet, o que Foucault (1987), em seu célebre livro Vigiar e punir, chamava de "docilização dos corpos", e ainda os horrores das guerras, é possível concluir que a violência não é propriamente um fenômeno contemporâneo: ela atravessa toda a história da humanidade.

Esse atravessamento da violência em nossas vidas se torna ainda mais visível quando nos acercamos do que a experiência analítica nos dá a ler como manifestações da pulsão de morte nos sonhos, em muitas das demonstrações mais bem intencionadas de amor familiar e da educação. Em outras palavras, se a Psicanálise, por privilegiar a fala e a linguagem, tem se dedicado mais a abordar e tratar a agressividade, também podemos afirmar que a clínica nos leva a situar, mesmo se tem mais registros sobre a agressividade, o quanto a violência se faz presente no próprio ser do que é humano, e isso se torna mais impactante quando, ao ler textos freudianos como Totem e tabu (Freud, 1913/1980), vamos descobri-la na própria origem da civilização. Assim, os psicanalistas poderiam estar menos surpreendidos pela tsunami de violência que devasta a terra e, em parte, a descoberta psicanalítica da violência no coração do ser de cada um que nos procura, poderia nos permitir leituras menos tomadas pelo pathos e por uma tendência ao conservadorismo ou seja, favorecer-nos abordagens bem diferentes de muitas daquelas 
que são estampadas cotidianamente nos meios de comunicação.

Sem dúvida, hoje, cada vez mais, presenciamos um aumento da violência. Porém, será que a diferença entre a violência atual e a de antes estaria limitada somente ao aumento da quantidade e da gravidade dos casos? Haveria mesmo algo, realmente novo na violência de nossos dias, particularmente se consideramos suas manifestações nas famílias e nas escolas? Respondendo rapidamente a essas duas perguntas, sustentamos que não é somente o aumento da quantidade de casos que angustia e produz pânico de um modo generalizado, mas também a maneira como a violência nos salta aos olhos.

Para abordar a questão, começaremos por algumas considerações preliminares sobre a violência cotejando-a com a noção de agressividade que, por sua vez, conta com um número muito maior de referências na Psicanálise. Em seguida, vamos nos deter na dimensão pública da violência familiar para, a partir de algumas perspectivas da orientação lacaniana, discutir a violência frente ao feminino e o feminino como saída frente à violência.

\section{Considerações preliminares}

A palavra violência deriva do verbo "violar", cuja raiz latina (vis) equivale à força. Segundo Chauí (2013), Aristóteles permite-nos a tematizar a violência como uma causa que produz um acontecimento contrário à natureza das coisas. Assim, a ação humana viola as leis da natureza quando, por exemplo, joga-se uma pedra para cima, contrariando o "destino natural" da queda dos corpos mais pesados que $o$ ar. Encontramos aí, não circunscrito apenas a essa definição aristotélica, porém mais articulado ao que pretendemos abordar, neste artigo, o paradoxo intrínseco à violência: ela é uma força que extrapola o que poderia ser considerado uma "tendência natural das coisas" e, nesse sentido, pode ser aproximada dessa força necessária para se arremessar a pedra para o alto na medida em que esta última reage contra a força "natural" da gravidade que provocaria a queda dita "natural" da pedra, mas, no caso da violência que é perpetrada e atinge os seres humanos, ela tampouco se opõe a outra força que poderia ser considerada "natural".

Quando passamos para o campo das forças que regulam a ação e os movimentos humanos, parece-nos decisivo, para tematizar e mesmo intervir sobre a violência, levar em conta a força da linguagem porque

O fenômeno da violência humana não é explicável por uma causa natural ou biológica como a que podemos atribuir ao mundo animal, seja pelo recurso a um instinto agressivo, a um 
instinto de domínio ou a um instinto de subsistência mais ou menos inato. A cultura humana, fundada na ação e nos efeitos simbólicos da linguagem sobre o corpo, desnaturaliza de tal maneira o registro biológico dos instintos que nenhum ato propriamente humano pode entender-se fora do registro simbólico e das significações que impõe a cada sujeito (Bassols, 2015, p. 79).

Com Lacan, podemos relacionar a estrutura de uma ordem, inclusive a do Estado de Direito, à ordem simbólica que, por excelência, é aquela que permite o pacto da comunidade humana. A entrada na linguagem - na qual a criança já nasce assujeitada - deve-se à operação significante que, como Lacan apontou, mortifica o sujeito na medida em que o afasta da experiência pulsional da qual foi objeto. Esse afastamento implica uma perda com relação a essa experiência localizada por Lacan no campo do gozo que, por sua vez, jamais se reduz à ordem estrutural da linguagem. Freud também já indicava isso ao caracterizar o objeto da satisfação pulsional como aquele desde sempre perdido. O ensino de Lacan sustenta que o gozo não pode passar todo pela rede da linguagem e escapa por suas brechas, por entre as palavras.

Como a ordem da linguagem se estabelece de forma cortante para a criança, as palavras comportam algo de violento e traumático pelo seu caráter de marcarem uma espécie de distância do corpo vivo em relação à experiência de satisfação que, assim como as palavras, também o afetam. Para Lacan, o trauma original dos seres humanos consiste justamente na entrada na linguagem, ou seja, na sua submissão à condição de falantes. Uma vez objeto da linguagem, violado por ela, cada um torna-se falante a partir de como experimentou a violência mítica original, para usar uma expressão de Benjamin (1921/2011), da entrada na ordem simbólica que legisla e parasita o organismo, transformando-o em corpo humanizado, habitado pela palavra. A incidência da violência se dá, em última instância, sobre o corpo na medida em que este se apresenta como campo de um gozo impossível de ordenar totalmente. Ela se dá tanto na tentativa de submetê-lo inteiramente à ordem, quanto na de eliminar o que escapa à ordem.

\section{Agressividade e violência, segundo Lacan}

É preciso destacar que, se não encontramos em psicanálise um trabalho conceitual já consolidado a respeito especificamente da violência, muitas elaborações já foram feitas, no entanto, sobre a agressividade. Em que, então, a violência se distingue da agressividade? 
Elas se distinguem pelo fato de que a agressividade é uma manifestação estruturada pelo campo da linguagem, enquanto que a violência se manifesta na ruptura com a linguagem e, nesse viés, no rompimento também com o laço social uma vez que este se trama pela linguagem. Para esclarecer essa distinção, partiremos da seguinte afirmação de Lacan (1957-1958/1999, p. 471): "o que pode produzir-se numa relação inter-humana são a violência ou a fala". No entanto, não parece haver aí uma oposição inteiramente antagônica. Há algo da destruição promovida pela pulsão de morte que permeia a fala e pode aparecer na forma de agressividade, mas essa destrutibilidade também pode se apresentar desligada da fala em situações nas quais o recurso à palavra fracassa na estruturação das relações humanas.

No caso da agressividade, como detalharemos adiante, encontramos o processo de identificação imaginária que, em algum ponto, falha. Veremos que há, na identificação imaginária, uma recusa de algo muito íntimo ao sujeito, relativo ao dualismo pulsional como também ao estranho corporificado pelo feminino, e que reaparece na imagem especular, na unidade do corpo próprio, como estranho e hostil. Nesse sentido, a agressividade se dirige a este ponto em que a identificação não dá conta de eliminar a destrutibilidade da pulsão de morte e a estranheza corporificada pelo feminino: ataca-se o outro como modo de preservar-se, conforme procuraremos demonstrar mais adiante, uma imagem supostamente unitária de si. Na violência, estamos num plano distinto com relação à lógica da identificação. 0 estranho e hostil, por não estar cingido pela rede de representações significantes, apresenta-se em seu caráter absoluto de Coisa, alteridade radical impossível de identificar, mas que pode ser experimentada como hostil. A pulsão de morte atua então na violência com muito mais intensidade que na agressividade.

A agressividade conta ainda com o que se passa no âmbito da fala, uma vez que põe em cena as identificações através das quais o sujeito se confronta com o objeto tomado como imagem do semelhante e/ou do rival, valendo-se de ordenamento relativo ao campo da linguagem e que define, por exemplo, o que pode ser "eu", o que pode ser "outro" e ainda o que faz com que "eu" e "outro" se confundam sem que suas referências se dissolvam completamente. A violência, por sua vez, faz desaparecer essas imagens que identificam, unem ou separam semelhantes e diferentes; por isso, ela pode ser melhor considerada, pela teoria psicanalítica, se a aproximarmos da articulação, sempre disjunta, entre sujeito e objeto no ponto em que a linguagem fracassa.

Nos interstícios da própria rede de linguagem, temos indícios da existência de pontos opacos, de furos na representação. Pontos que atestam um relativo fracasso da linguagem em relação à experiência pulsional que acontece no corpo. Se esses furos permanecem como 
tais, enredados pela estrutura da linguagem, pode haver uma hostilidade em relação a eles configurando a agressividade; porém, se uma manifestação pulsional conta apenas precariamente ou sequer pode se valer de algum recurso às palavras para bordejá-la, essa ruptura com a linguagem ou com a fala faz prevalecer a violência, inclusive sobre a própria agressividade.

No que concerne mais especificamente ao modo como imagem, linguagem e agressividade se conectam, parece-nos imprescindível retornar ao que Lacan (1949/1998, p. 99) situava, antes mesmo do início formal de seu ensino, como o "problema da significação do espaço para o organismo vivo" - no termo "significação", já podemos detectar a presença da linguagem e, como veremos a seguir, quando esse "organismo vivo" diz respeito aos humanos, as relações entre rivalidade, imaginário e agressividade também serão destacadas. Para abordar tal "problema da significação do espaço", Lacan recorreu, inicialmente, a um texto de um sociólogo chamado Roger Callois (1938/1989, p. 107-08) porque este inverte a tese mais convencional que temos sobre o mimetismo: em vez de tomá-lo como uma defesa que ajuda certos animais a sobreviverem a seus predadores, constata-se que o animal mimético visa ao semelhante e que, buscando esse semelhante, se faz assimilar ao meio, mas "como se fosse um encantamento fixado em seu ponto culminante", no qual "o feiticeiro é capturado pelo seu próprio feitiço", em sua própria feitiçaria.

Assimilado, então, a seu meio, o animal mimético é atraído por "uma verdadeira tentação do espaço" (Callois, 1938/1989, pp. 108-109) e - é sobretudo isso que gostaríamos de ressaltar - ele se deixa levar por "uma provocação ao canibalismo" (Callois, 1938/1989, p. 106), quer dizer, entrega-se à própria destruição. Assim, a assimilação da mariposa Caligo a uma coruja pode livrá-la de alguns predadores, mas faz com que seja presa fácil tanto dos indígenas que a capturam para espantar os maus espíritos, quanto dos pássaros que, assustados com os "olhos" estampados nas asas dessa mariposa, a devoram rapidamente. Também as lagartas Phyllia, tão atraídas pelas folhas que thes servem de alimento e com as quais se assemelham, terminam por se fazerem devorar umas as outras, segundo Callois (1938/1989, p. 110), "em uma espécie de masoquismo coletivo". O ser vivo, então, nos ensina Callois (1938/1989, p. 110), perde "a origem das coordenadas", sua própria localização, transforma-se "em um ponto entre os outros" e "não sabe mais onde se localizar".

Com Callois lido por Lacan, podemos verificar como, muitas vezes, a agressividade pode passar à violência devido a uma perda das raízes, dos referenciais, da localização. Callois também foi tão importante para Lacan porque chegou a aproximar o mimetismo dos casos psicopatológicos em que se perde o "sentimento de personalidade" que, numa perspectiva muito materialista e diferente da acepção 
psicologizante do termo "personalidade", foi considerado como "sentimento da distinção do organismo em sua relação ao meio" (Callois, 1938/1989, pp. 110-111). Uma vez perdido, tal sentimento comprometia gravemente o "sentimento da vida" (Callois, 1938/1989, p. 110-111) fazendo o espaço se impor como "uma potencia devoradora" ao ponto de, "em uma fagocitose gigante" (Callois, 1938/1989, p. 111), engolir o próprio organismo vivo, mas perdido quanto à localização de suas coordenadas.

Passando dos estudos de Callois com animais miméticos para as situações humanas, podemos conceber a nuance sutil entre agressividade e violência, propondo que a pulsão destrutiva, por trás dos cenários de identificação onde referências e localizações ainda se mantêm, resta em parte mais recoberta. Assim, a cena agressiva nos dramas de rivalidade, inveja e ciúme recobre e escamoteia o conflito mortífero entre o sujeito e o objeto. É o que Lacan destaca quando aponta que, para fazer uma distinção entre violência e agressividade, é preciso

saber em que medida a violência como tal - para distingui-la do uso que fazemos do termo da agressividade - pode ser recalcada, uma vez que postulamos como princípio que só pode ser recalcado, em princípio, aquilo que revela ter ingressado na estrutura da fala, isto, a uma articulação do significante (Lacan, 1957-1958/1999, p. 471).

Logo, os relatos e situações tomados pela agressividade podem ser lidos como narrativas de cifração inconsciente para conter a virulência da pulsão de morte que os anima. Por sua vez, quando a violência explode (ou mesmo implode), é porque as referências identificatórias e de localização são precárias ou até desparecem como tentativas de conter essa virulência. Assim, a violência escapa àquilo que se refugia sob a capa da identificação, testemunhando o encontro com um objeto em sua absurda estranheza e que não se apresenta mais como um semelhante ou mesmo um rival, mas como alteridade radical, diante da qual o sujeito corre o risco de ser literalmente esmagado. Frente a essa presença ameaçadora, 0 sujeito pode perpetrar 0 ato de abolir o objeto estranho, por vezes abolindo-se com ele, na medida em que não conta com o recurso às palavras, ou seja, com as tessituras narrativas que o mantém de algum modo distante desse objeto de horror.

De certa forma, a violência é uma defesa do sujeito. Isso não coincide com a concepção de defesa no discurso jurídico, nem justifica, por si só, o recurso à violência usado pelo sujeito em sua defesa, mas indica o ponto de real, ao qual a violência responde. Trata-se de defesa contra o real do gozo indistinto e inconcebível. Vemos, então, que a violência está além e aquém da linguagem, ou 
seja, nos limites de seu alcance, como Lacan situa ao perguntar: "Acaso não sabemos que nos confins onde a fala se demite começa o âmbito da violência, e que ela já reina ali, mesmo sem que a provoquemos?" (Lacan, 1954/1998, p. 376). Podemos sustentar que essa pergunta de Lacan já comporta sua própria resposta porque, no trecho inicial relacionado aos "confins onde a fala se demite" e ao começo "do âmbito da violência", encontramos a distinção falaviolência, ou seja, onde há fala, não há violência e onde há violência é porque houve demissão da fala; por sua vez, no último trecho "ela já reina ali, mesmo sem que a provoquemos", reitera-se que, mesmo sem ser provocada, a violência reina, silenciosa como a pulsão de morte, quando há impedimento (ou mesmo apagamento) da fala.

\section{Do privado ao público: o espaço da violência}

Há um regime de transparência que rege a vida atual. O privado passou a ser uma questão pública. Nesse sentido, já não podemos adjetivar tão facilmente a violência na família de doméstica, como há muito tempo se tem feito. O adjetivo "doméstica" traz a marca do espaço familiar no qual, supostamente, a violência não podia se adentrar com tanta facilidade. A violência contra a mulher e as crianças na família não era desconhecida. A vizinhança da comunidade sabia de sua existência, mas a ideologia sexista a normatizava, considerando-a "natural". Constituía-se assim um saber compartilhado, embora não devesse ser tornado público, segundo tal ideologia (Dupuy, 2014, p.101).

Esta é uma distinção que gostaríamos de fazer, sem retornar a uma posição sexista, tomando como parâmetro a experiência analítica e suas possíveis contribuições para responder o que se apresenta hoje como violência: nem todo saber compartilhado é, ou deve ser, necessariamente público. Tornar certos saberes públicos tem sido a bandeira de muitas lutas por direitos, em geral, das minorias. Assim, se a violência na família tinha seu lugar restrito ao espaço privado das parcerias amorosas mais íntimas, foi devido à luta pelos direitos da mulher, da criança e do adolescente que ela passou da esfera de doméstica para se tornar assunto público. Essa passagem não deixou de colaborar muitíssimo para a institucionalização da vítima. Emprega-se o termo vítima para falar de uma pessoa morta ou ferida por força de cataclismo, acidente ou violência. O último sentido é dominante em nossos dias e uma rede de atenção à vítima é montada e sustentada a partir de ideais contemporâneos de prevenção e terapêutica.

No Brasil, por exemplo, as questões das mulheres começaram a ter fóruns próprios desde a década de 1980. Mas a violência contra a mulher só começa a receber um tratamento diferenciado a partir da 
instauração de uma lei, em 2006, intitulada Lei Maria da Penha devido ao nome de uma mulher, baleada pelo marido. Foram precisos 20 anos de luta jurídica para que o crime fosse punido. A questão alcançou repercussão internacional fazendo com que a Organização dos Estados Americanos (OEA) pressionasse o Brasil a propor modificações jurídicas no tratamento dado até então a esse tipo de violência. A história da promulgação da Lei Maria da Penha ilustra bem a mudança de tratamento dado à violência contra as mulheres nas últimas décadas. Afinal, a partir dessa Lei, o saber compartilhado, mas submetido ao silêncio público que fazia dele um segredo de família, passa a ser um saber que se deve tornar público. Passa-se do que deve ser segredado ao que deve ser denunciado e, daí, ao encorajamento da denúncia do qual o serviço do "disque denúncia" é um exemplo.

As próprias mulheres atingidas participavam desse segredo e tinham enorme dificuldade em reportar os episódios sofridos, desencorajadas pelo pouco caso e preconceitos dos quais seriam alvos caso o fizessem. Era uma questão de vergonha. Esse quadro ainda não é muito distante do atual, pois ainda há dificuldade em denunciar a violência sofrida. Mas não parece ser apenas pelo entrave da vergonha. Para a psicanálise, a vergonha se articula ao recalque e, portanto, à responsabilidade do sujeito sobre seu gozo. Um gozo recalcado, ignorado, impossível de ser assimilado, um segredo, se o tomamos na lógica freudiana do recalque. No entanto, com Lacan, deslizamos do segredo do recalque para o silêncio concernente ao real: mesmo que a pessoa violentada admita sua parcela de responsabilidade por se manter na situação potencialmente produtora de violência, ela, em muitos casos, não pode saber e menos ainda exprimir em palavras a pulsão de morte que a imobiliza impedindo que evite ou saia da parceria violenta.

E preciso considerarmos, então, que, mesmo em tempos de denúncia generalizada, muitos episódios de violência tocam 0 insensato, 0 indistinto e indefinido do gozo: o gozo feminino, segundo Lacan. Esses episódios implicam não um segredo, mas um silêncio, quanto ao real. $O$ empuxo contemporâneo à transparência e à terapêutica trata a violência como se bastasse falar, denunciar, julgar e punir, torná-la necessariamente pública, visível. A aposta é que se possa falar tudo e nisso consistiria a cura, a solução. Com isso, não se leva em consideração aspectos do real do gozo, presentes nas parcerias. Observamos então um empuxo às práticas confessionais, imediatistas e assistencialistas que desconsideram inteiramente o campo do gozo.

$\mathrm{O}$ cientificismo atual também tem seu papel nisso. Exige-se controle e domínio de tudo. Não há lugar para o risco, o inesperado, o fora do sentido. Desse cientificismo deriva 0 afã pela prevenção em associação a uma terapêutica que seja breve. Assim, uma variedade de dispositivos é colocada à disposição das vítimas. Com a oferta, 
cria-se uma demanda. Observa-se, no entanto, que, se os dispositivos são muitos, suas falhas também são. A complexidade de uma rede em que tudo deva funcionar bem põe em relevo sua ineficácia. Quando há exigência de controle, o descontrolado ganha destaque, tal como podemos encontrar nos imperativos do supereu: passamos da busca pelo controle da violência ao supereu insaciável que não cessa de apontar à violência e ao fracasso em controlá-la.

\section{Um paradoxo topológico: efeitos sobre a violência nas famílias}

Outro aspecto que mostra como a violência atual não é a mesma que a de antes deve-se ao fato de sofrermos cada vez mais dos efeitos devastadores do que Lacan, já em 1967, nos alertava nos seguintes termos:

Os homens estão enveredando por uma época que chamamos planetária, na qual se informarão por algo que surge da destruição de uma antiga ordem social, que eu simbolizaria como império, [...] para ser substituída por algo bem diverso e que de modo algum tem o mesmo sentido - os imperialismos, cuja questão é a seguinte: como fazer para que massas humanas fadadas ao mesmo espaço, não apenas geográfico, mas também, ocasionalmente familiar, se mantenham separadas (Lacan, 1967/2003, pp. 360-361).

Comentaremos essa citação destacando-Ihe duas passagens. Assim, há algo de novo em nossa violência porque, diferente do que tínhamos antes, ela toma agora uma dimensão planetária, ou seja, não é somente um aumento da quantidade de casos, mas também da extensão de onde a violência irrompe - ela se faz planetária ou, para utilizar um termo de nossos dias, global. E ela se processa ainda segundo um paradoxo topológico (se podemos qualificá-lo dessa maneira): as massas humanas, ainda que vivam em um mesmo espaço, são mantidas como se estivessem separadas, e - podemos acrescentar agora para voltar a este ponto mais adiante - separadas de um modo anônimo.

Considerando esse paradoxo topológico localizado por Lacan e levando em conta sempre sua perspectiva planetária, como podemos reconhecê-lo na família? De início, ressaltamos sua presença na arquitetura e no urbanismo contemporâneos. Nas classes sociais média e baixa, cada vez mais os espaços de convivência, as casas e apartamentos são menores. Esses espaços podem ainda se reduzir ao ponto de sequer existirem, como nos provam os "sem teto" (homeless). Verificamos também o quanto cada vez menos os 
membros de uma mesma família compartilham realmente esses lugares minúsculos ou inexistentes, cada vez menos se promovem encontros dignos do nome "encontro" e nos quais a palavra poderia ao mesmo tempo circular e registrar algo que escapa, mas que importa aos seres atravessados pela língua. Sublinhamos que isso que a palavra poderia ao mesmo tempo fazer circular e registrar diz respeito ao gozo. E ainda que caiba aos chamados "ricos" viverem em espaços cada vez mais amplos, essa amplitude não faz com que os lugares de encontro lhes sejam mais presentes nas vidas.

A segregação, portanto, está em todos os lugares e classes sociais e, para a psicanálise, nem sempre coincide com uma precariedade social ou com uma situação marginal qualquer: ela se impõe quando os seres que, embora tomados pela palavra, muitas vezes deixam de falar do que realmente importa na vida, ou seja, de suas reais satisfações, de seus anseios, do que Ihes ultrapassa - o gozo e o desejo.

A solução, então, não se efetiva, por exemplo, somente com a mudança arquitetônica dos espaços. Ainda assim, algumas mudanças no espaço podem evidenciar modificações importantes: certa vez, no Instituto de Psicanálise e Saúde Mental de Minas Gerais (IPSM-MG), o sociólogo Cláudio Beato, coordenador do Centro de Estudos de Criminalidade e Segurança Pública da Universidade Federal de Minas Gerais, apresentou dados de como, por exemplo, na Praça da República, localizada em São Paulo, há um grande número de assaltos, mas, se descermos para tomar o metrô, alguns metros abaixo dessa mesma praça, temos uma ilha de tranquilidade, ou seja, a violência decresce quando o espaço muda e aparece, alguns metros abaixo da Praça da República, mais limpo e organizado.

Os meios de comunicação, nossa prática clínica ou o trabalho nas instituições de saúde, de educação e jurídicas nos mostram vários casos nos quais percebemos que, no mesmo mundo em que as crianças são cada vez mais valoradas como objetos de atenções especiais e profissionais, há também um aumento progressivo das agressões às crianças e que provocadas, sobretudo, por suas próprias mães, terminando, inclusive, em mortes. Em outras palavras, 0 suposto laço mãe-filho(a), ainda que evoque um espaço familiar, não se mostra mais suficiente para que a mãe não se afaste violentamente da criança que gerou: há mães, há filhos, porém esses nomes parecem não nomear efetivamente mais ninguém, tampouco sustentar laços. Os abusos tão divulgados atualmente são tipos de violência familiar que se impõem porque houve dissolução dos laços entre pais e filhos, mesmo que a família permaneça existindo. 0 problema é que cada vez mais as famílias são tomadas pelo "paradoxo topológico" da segregação já assinalado por Lacan no final dos anos 1960. 


\section{Perspectivas a partir da orientação lacaniana}

Em um primeiro momento de seu ensino, Lacan apontou à dimensão simbólica da alteridade, senão como uma solução, seguramente como uma regulação do problema da atração que o espaço, como o semelhante, exerce sobre os seres humanos. Assim, embora não sejamos biologicamente miméticos, o somos subjetivamente devido a nossa relação especial com um corpo; ainda que esse corpo seja denominado como nosso, ele se mostra a todo o tempo como estrangeiro ${ }^{1}$. Nesse contexto, o Outro simbólico, a Lei simbólica, o Nome-do-Pai eram recursos para não ser consumido pela fagocitose espacial e imaginária.

De certa maneira, embora considerado por muitos ainda ilegível, é esse Lacan que se tornou clássico e mais conhecido pelo privilégio atribuído à "ordem simbólica", pela organização e o norteamento promovidos pelo "Nome-do-Pai". É ainda a esse Lacan, inclusive sem nomeá-lo diretamente ou sem conhecê-lo efetivamente, que recorrem os nostálgicos do Pai, da Lei e de um Mundo que não existiria mais. Localizamos, nessa nostalgia, as várias e quase sempre inúteis tentativas de se diferenciar, em nossos dias, a autoridade do autoritarismo ou de tratar a desorganização do mundo contemporâneo, presente nos casos de violência, pela reeducação que visaria a "fazer aceitar os limites" e pelas vãs tentativas de "salvar o Pai" almejando um funcionamento ideal das leis.

A ação lacaniana, diante da violência no mundo contemporâneo e da própria forma como essa violência se irrompe, nos impele a outra perspectiva. Essa outra perspectiva, no entanto, não nos impede de recorrermos à dimensão simbólica da autoridade, desde que não a confundamos com a mera aceitação de limites socialmente definidos. Aproveitando o que Callois (1938/1989) nos diz sobre a perda do sentimento da vida, diríamos que é à vida que deveremos nos dirigir, una vida mais além da sobrevivência cotidiana e sem a qual a própria decisão pela sobrevivência acaba por perder qualquer atrativo. Nesse sentido, o "sentimento da vida" para Lacan não se separa de sua própria crítica ao sentimento que ele escande, em francês, como "senti-ment": podemos dizer, então, que há nos sentimentos algo que mente (ment) (Lacan, 1975-1976/2007, p. 37) e, no caso do sentimento da vida, para que ele seja experimentado como uma presença efetiva, trata-se de deixar-se guiar pelo real da vida que inclui o que escapa.

A partir da teorização de Lacan sobre a diferença sexual em termos de modalidades de gozo, gostaríamos de articular então "isso que escapa" e o "gozo feminino", para abordarmos o feminino, tantas vezes alvo de violência, como aquilo que se opõe à lógica fálica e que se torna bastante afetado pelos efeitos do declínio da função paterna no mundo contemporâneo. Entre esses efeitos, como vimos, temos a 
forma muitas vezes desmedida e avassaladora com que a violência irrompe hoje. Duas questões se destacam e nos norteiam para avançar nas perspectivas de orientação lacaniana com relação à violência: por que o feminino tão ameaçador e, portanto, com tanta frequência, é alvo de violência? Como este mesmo feminino pode oferecer uma saída para a violência que provoca?

\section{A violência frente ao feminino e o feminino como saída frente à violência}

Atestando a força da violência contra as mulheres, tivemos recentemente o reconhecimento jurídico de um tipo de crime chamado "feminicídio" 2 para caracterizar os assassinatos de mulheres por homens que as consideram "sob sua dominação". Esse tipo de crime convoca-nos a investigar melhor a questão sobre a íntima relação entre a violência e o feminino. Essa relação ganha expressividade, por exemplo, nas estatísticas que situam as mulheres como majoritariamente vítimas de violência ${ }^{3}$. Na perspectiva lacaniana, recolhemos nas raízes dessa tendência o que Freud assinalou, na constituição dos sujeitos, tanto homens como mulheres, de repúdio ao feminino (Freud, 1937/1987, p. 285). No entanto, o feminino não pode ser confundido com o termo "mulher", tampouco com o que o definiria a partir da anatomia. Com o ensino de Lacan, especialmente nas suas fórmulas da sexuação (Lacan, 19721973/1985), o feminino se descola do corpo anatômico e da categoria de gênero na medida em que habita, a rigor, todos os corpos, sendo, no entanto, subjetivado de forma singular por cada um.

Podemos tomar o objeto como um ponto de localização para situar o feminino sem querer, no entanto, que o feminino se reduza ao objeto e muito menos ainda confundi-lo com a posição passiva, o que o próprio Freud não fez, ainda que muitas das críticas à sua teoria tenham se baseado nessa leitura errônea do termo passivo. Na verdade, Freud aponta que colocar-se numa posição passiva em um circuito pulsional, demanda muitíssima atividade do sujeito e dá exemplos disso a partir do exibicionismo e do masoquismo. Aproximamos, então, o feminino da posição de objeto uma vez que este implica que o sujeito, através da lógica da linguagem, no próprio ato e ao mesmo tempo em que discerne um objeto, determina também seu avesso, o que lhe escapa. O objeto para um sujeito resulta dessas duas operações. Por um lado, ele deriva de uma discriminação significante, uma espécie de "é isso" que o localiza e o identifica no campo da linguagem; por outro lado, ele escapa ao que se pode distinguir e nomear no campo do gozo que promove.

Com Lacan, encontramos esse paradoxo no matema da fantasia $(\$<>a)$, um amboceptor, como o qualifica Miller (2011) que conjuga, 
ao mesmo tempo, o lado significante que nomeia o objeto e o lado inominável do gozo que este objeto desperta. Quando Lacan (19721973/1985) vai tratar da sexuação, situa a fantasia colocando o sujeito dividido (\$) do lado fálico (masculino) e o objeto a do lado do Outro gozo, ou seja, do lado feminino que é tomado, então, não apenas por esse objeto cuja pregnância encontramos nessas situações em que uma mulher é reduzida a um "objeto sexual" ou mesmo a um "objeto de maltrato", mas ainda por um Outro gozo em relação ao gozo fálico que se pode nomear. É, sobretudo, essa permeabilidade ao inominável que faz Lacan situar, no lado feminino da tábua da sexuação, tanto a inconsistência do Outro ( $\mathbf{A}$ ) quanto a marca significante dessa inconsistência, ou seja, $\mathbf{S}(\mathbb{A})$.

Os circuitos e mesmo os impasses da satisfação feminina, portanto, não se apresentam pura e simplesmente pelas circunstâncias em que, por exemplo, uma mulher é reduzida ou se reduz ao objeto a da fórmula da fantasia. Eles ainda respondem a essa inconsistência que Lacan (1972-1973/1985) pôde também situar do lado feminino da tábua da sexuação, graças à experiência analítica e à sensibilidade feminina ao que historicamente se designou como "gozo místico". Lacan oferece-nos, portanto, no âmbito das diferenças sexuais, uma forma de distinção muito especial, pois não se trata mais daquela freudiana que opõe o fálico ao não-fálico, a ausência da castração à presença da castração. Na distinção proposta na tábua da sexuação, não temos uma comutação de termos, mas uma ultrapassagem, melhor dizendo, uma suplementação para usar o termo de Lacan. Mostramos, abaixo, uma versão reduzida da tábua da sexuação, concentrada mais nas letras encontradas no matema lacaniano da fantasia ( $\$<>$ a) e no duplo vetor que parte da posição feminina, para a qual não se tem um universal $(\mathbf{A})$, em direção ao falo ( $\Phi$ encontrado do lado masculino, mas que segue também, em sua ultrapassagem, do lado feminino, em direção à inconsistência do Outro (A).

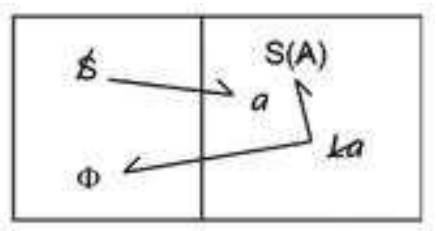

Assim, feminino designa, em primeiro lugar, uma modalidade de gozo em uma posição que, por ser de ultrapassagem, pode colocar, a nosso ver, em risco o sujeito: há uma experiência de satisfação no corpo, mas ela não se deixa propriamente subjetivar, escapa à significação e pode tomar a forma de algo inominável. Essa posição varia segundo as contingências e, assim, alguns corpos anatomicamente considerados femininos ou não - podem consentir 
em serem tomados mais por ela que outros. Vale lembrar que, para Lacan, o sujeito atravessado por uma divisão não está identificado a um significante no qual se reconheceria plenamente, ou seja, sem divisão. Assim, essa divisão do sujeito parece-nos impeli-lo ao feminino, no que este pode seduzi-lo como gozo misterioso ou ainda assustá-lo como gozo ameaçador. A identificação capaz de conferir ao sujeito alguma ideia de unidade se articula mais propriamente ao eu, à imagem que ele passa a tomar como sua, mas que, primordialmente, como verificamos nas crianças antes dos dezoito meses de idade, não the serve como um reconhecimento de si e tem mais a ver com o que lhe aparece como se fosse um outro. Logo, como já notava Callois (1938/1989), o espaço é tão atraente porque é nele que se forma essa imagem onde o sujeito encontra um refúgio, mas esse refúgio não lhe é menos ameaçador porque a imagem de si é, efetiva e primordialmente para ele, um outro. Subjacente a toda identificação há, portanto, uma vacilação subjetiva que é incômoda. Uma vacilação que balança o cômodo lugar das identificações.

Essa vacilação pode remeter o sujeito a atos agressivos, quando ele encontra no outro ou em alguma imagem de si, mesmo por oposição, uma referência que parece tentar destituí-lo, mas também a atos violentos dirigidos ao outro que, localizado então como objeto ameaçador ou como um campo inconsistente, não the oferece recursos nem à identificação, nem à palavra. São especialmente nesses atos violentos que nos parece possível detectar uma recusa do feminino inerente à própria vacilação subjetiva. Dessa forma, a nosso ver, o sujeito tomaria, por exemplo, uma pessoa como objeto para tenta extrair do próprio corpo aquilo que não lhe é muito fácil de subjetivar e que se apresenta para ele como estranhamente Outro. Há uma coisificação do outro como uma tentativa de resposta a uma "coisa", a algo estranho experimentado no corpo.

A violência seria então, em muitas situações, uma forma de alguém recusar o feminino em seu corpo, atacando-o no corpo daquele a que se supõe a posição feminina. Nesse sentido, o que Lacan (19721973/1985) chamou de gozo feminino afeta o corpo de cada um, independente da anatomia ou do gênero, e pode ser experimentado de forma ameaçadora porque traz para o corpo a presença de um ultrapassamento, de uma estranheza, de um Outro que nem sempre se consegue propriamente localizar, nomear. O que há de masculino nessa operação da violência é a tentativa de dominar esse gozo (experimentado como alheio, estrangeiro, enigmático, opaco) por uma exclusão do corpo, localizando-o no corpo do Outro. Temos, de certa forma, a mesma estrutura básica da paranoia, embora não se trate aqui de usar este termo como uma classificação da nosologia, mas de apontar à vacilação subjacente à identificação do eu. $\mathrm{Na}$ paranoia, isso é evidente justamente porque a identificação do eu é 
extremamente precária. No entanto, mesmo quando a identificação é bem-sucedida e recobre uma divisão subjetiva, esta pode, com frequência, ameaçá-la. As identificações são, nesse sentido, como um pharmakon: remediam a vacilação do sujeito, pois decidem e localizam um lugar no mar de significantes e na profusão de imagens que Ihe são apresentadas na cultura, mas portam um fator letal, pois qualquer escolha se dá sob o pano de fundo da inexistência de " $\mathrm{O}$ " significante, de " $A$ " imagem ou de "O" objeto capazes de aplacar tal vacilação.

A cada identificação, portanto, temos um correlato de segregação e destruição. Quanto mais classificações de identificação temos, mais violências podem surgir levando à segregação, porque tais classificações tendem a legitimar suas modalidades de gozo em detrimento de outras. Revela-se assim a problemática do sujeito ao tentar sair de sua divisão subjetiva pela identificação: quanto mais forte é o movimento de identificação, maior a exigência de apagamento do resto que lhe escapa. Segundo essa leitura, a violência atual pode atingir muito as mulheres pelo que estas se aproximam da posição feminina, assim como as crianças que nascem nessa posição, mas também os loucos e os estrangeiros que, cada qual a seu modo, carregam em seus corpos o que se apresenta muitas vezes como inclassificável, inominável.

Tendo em vista essa problemática da identificação, podemos propor que a classificação "violência de gênero" é precária para tratar as experiências que ela pretende designar. Inegavelmente, é necessário o trabalho social e político de empoderamento da mulher dando a ela as condições essenciais de cidadania para que possa escolher seus modos de vida como um sujeito do direito. Mas isso nem sempre responde singularmente à satisfação pulsional que também está em jogo nas situações de violência. Ao mesmo tempo, tal trabalho de empoderamento tem seu lugar porque, quando o direito da escolha se faz valer, é que, sob o ponto de vista do sujeito do inconsciente, as manifestações insondáveis da pulsão podem ser mais bem delineadas.

Já procuramos demonstrar acima que, diante da estranheza de estar na posição feminina ou de se ver afetado por ela, uma das estratégias é a de localizar o feminino fora do corpo, confundindo, com o corpo alheio, o que acontece no próprio corpo como estranho. Sem o recurso a esses meandros por onde passa, não sem tensões e trajetos inusitados, a satisfação das pulsões, ficamos presos às identidades estanques do tipo "agressor" e "vítima", "sexo forte" e "sexo frágil", "violência de gênero", etc. A rigor, a violência atinge aquele, seja quem for, que se encontra na posição feminina, o que é diferente de dizer que a mulher é sempre a vítima e, se muitas vezes os fatos constatam esse tipo de identificação entre "mulher" e "vítima", é porque o corpo feminino não deixa de ser tomado, mesmo 
com todos os avanços já conquistados, como um "corpo estranho". Agressor e vítima podem ser, então, protagonistas de um mesmo tipo de discurso. Daí, também, um modo de elucidar a vacilação de, por exemplo, muitas mulheres com relação aos parceiros que as tomam como objetos de violência: elas os acusam, mas em seguida reatam com eles, pois com frequência, ainda que de forma inconsciente, 0 que leva à violência da parceria é compartilhado por ambos.

Na violência se trata, sobretudo, de uma posição diante do Outro do qual as mulheres, ainda que não as únicas, são consideradas como boas figurantes. Assim, parece-nos oportuno apontar que os protagonistas da violência parecem abordar a mulher como aquela que

"é o Outro que não tem, o Outro do não-ter, o Outro do déficit, da falta, o Outro que encarna a ferida da castração, o Outro atingido em sua potência. A mulher é o Outro diminuído, o Outro que sofre $e$, por esse viés, igualmente o Outro que obedece, que se queixa, que reivindica, o Outro da pobreza, do desnudamento, da miséria, o Outro do qual se rouba, com o qual se falta, que se vende, no qual se bate, que se mata.... 0 Outro submetido, e que não tem nada a dar, exceto sua falta e os signos de sua falta" (Miller, 2015, p. 116).

Voltando ao tema do empoderamento, podemos agora estimar o que a psicanálise lacaniana pode propor, além do que é fomentado pelas teorias e políticas de gênero, como contribuição ao combate à violência contra as mulheres. Já assinalamos os bons efeitos do empoderamento, mas, em si, ele não nos parece mudar substancialmente a lógica segregacionista quando a inserimos nos meandros inquietantes da satisfação pulsional porque, nesse âmbito nem sempre evidente no que é socialmente apresentado, o empoderamento pode apenas trocar os personagens de lugar. Isso pode ser atestado pelo fato de que as mulheres têm se tornado mais fortes e poderosas ou, em termos psicanalíticos, fálicas, resultando também, conforme sustenta Solano-Suarez (2015), um significativo aumento da violência entre casais nos quais a mulher é a agressora e o homem, a vítima.

Nesse sentido, podemos nos valer de uma indicação de Lacan (1973/2003, p. 533). Ao preconizar a escalada do racismo (que estendemos aqui ao sexismo) ao propor: "deixar esse Outro entregue ao seu modo de gozo, eis o que só seria possível não lhe impondo o nosso". O desafio dessa proposta implica em jogar com outra lógica distinta da lógica do reconhecimento na qual a reciprocidade é uma exigência. Miller aponta que 0 racismo se dá pela falta de reciprocidade que o reconhecimento exige, ele "é a recusa de reconhecer que o outro poderia compreender o sentido do que lhe 
digo" (Miller, 2010, p. 62). Como a compreensão é sempre precária, o reconhecimento sempre falha e algo opaco do gozo se destaca. Para lidar com isso sem cair na posição de recusa, Miller evoca o termo disparidade usado por Lacan (1960-1961/1992) para frisar o que encontramos na palavra inglesa odd (díspar, ímpar) que se distingue da reciprocidade procurada pelo reconhecimento imaginário que, como mostramos com a leitura lacaniana de Callois (1938/1989, p. 106), pode terminar sempre em "canibalismo". Segundo a disparidade, a diferença se abre ao que não tem sentido fixo ou rígido, ao que ainda está por se saber, e daí, uma impossibilidade para ser re-conhecida, mas que não é experimentada sem o recurso às palavras (mesmo que no limite delas), sem um enfrentamento decidido da inconsistência do Outro. Nesse viés da disparidade, mulheres (ou mesmo homens) em posição de decisão poderiam agir de modo diferente de apenas usar do poder que demanda a posse e 0 controle. Nossa aposta é de que se possa fazer outro uso de experiências subjetivas ligadas ao gozo feminino uma vez que este é singular e, além disso, opaco ao saber. Essa possibilidade de lidar com o que não se sabe poderá, a nosso ver, não apenas abrir mais vias para criatividade como também permitir um enfrentamento ético e mais consequente dos riscos anunciados por ameaças nas quais os sujeitos acabam abolidos. Nesse sentido, no que concerne mais singularmente às mulheres, a luta frente à violência poderá não se reduzir à batalha, por vezes oportuna, de controle, prevenção ou mesmo punição do que é violento. Afinal, como procuramos demonstrar aqui, esse tipo de batalha acaba por reiterar, em muitas situações, a posição das mulheres como vítimas privilegiadas da violência. Norteados pelo ensino de Lacan, estimamos, sobretudo, que outro tipo de enfrentamento da violência poderá ter lugar quando, pautadas em suas singularidades, as mulheres consentissem em sustentar uma forma de fazer laço social a partir da sua modalidade própria de gozo e de suas disparidades.

\section{Referências}

Bassols, M. (2015). A violência contra as mulheres: questões preliminares a seu tratamento a partir da psicanálise. Correio: Revista da Escola Brasileira de Psicanálise, 76, 79-82.

Benjamin, W. (2011). Para uma crítica da violência. Escritos sobre mito e linguagem (pp. 121-156). São Paulo, SP: Duas cidades. (Originalmente publicado em 1921).

Callois, R. (1989). Mimétisme et psychasthénie légendaire. Le mythe et I'homme (pp. 86-122). Paris: France: Gallimard. (Originalement publié en 1938).

Chauí, M. (2013). Servidão voluntária ou o mau encontro. In Escritos 
de Marilena Chaui (Vol. 1, pp. 111-135). Belo Horizonte, MG: Autêntica.

Dupuy, J. P. (2014). O silêncio público. Mutações: o silêncio e a prosa do mundo (pp. 97-113). São Paulo, SP: Edições Sesc São Paulo.

Foucault, M. (1987). Vigiar e punir: nascimento da prisão. Petrópolis, RJ: Vozes.

Freud, S. (1980). Totem e tabu. In S. Freud (Ed.), Edição standard brasileira das obras psicológicas completas de Sigmund Freud (Vol. 13, pp.17-192). Rio de Janeiro, RJ: Imago. (Originalmente publicado em 1913).

Freud, S. (1980). Sobre o narcisismo: uma introdução. In S. Freud (Ed.), Edição standard brasileira das obras psicológicas completas de Sigmund Freud (Vol. 14, pp. 89-119). Rio de Janeiro, RJ: Imago. (Originalmente publicado em 1914).

Freud, S. (1980). Análise terminável e interminável. In S. Freud (Ed.), Edição standard brasileira das obras psicológicas completas de Sigmund Freud (Vol. 23, pp. 247-289). Rio de Janeiro, RJ: Imago. (Originalmente publicado em 1937).

Lacan, J. (1985). O seminário, livro 20: Mais, ainda. Rio de Janeiro, RJ: Jorge Zahar. (Originalmente publicado em 1972-1973).

Lacan, J. (1992). O seminário, livro 8: a transferência. Rio de Janeiro, RJ: Jorge Zahar. (Originalmente publicado em 1960-1961).

Lacan, J. (1998). O estádio do espelho como formador da função do eu. In J. Lacan (Ed.), Escritos (pp. 96-103). Rio de Janeiro, RJ: Jorge Zahar. (Originalmente publicado em 1949).

Lacan, J. (1998). Introdução ao comentário de Jean Hyppolite sobre a 'Verneinung' de Freud. In J. Lacan (Ed.), Escritos (pp. 370382). Rio de Janeiro, RJ: Jorge Zahar. (Originalmente publicado em 1954).

Lacan, J. (1999). O seminário, livro 5: as formações do inconsciente. Rio de Janeiro, RJ: Jorge Zahar. (Originalmente publicado em 1957-1958).

Lacan, J. (2003). Alocução sobre as psicoses da criança. In J. Lacan (Ed.), Outros escritos (pp.359-368). Rio de Janeiro, RJ: Jorge Zahar. (Originalmente publicado em 1967).

Lacan, J. (2003). Joyce, o Sintoma. In J. Lacan (Ed.), Outros escritos (pp. 560-566). Rio de Janeiro, RJ: Jorge Zahar. (Originalmente publicado em 1979).

Lacan, J. (2003). Televisão. In J. Lacan (Ed.), Outros escritos. Rio de Janeiro, RJ: Jorge Zahar. (Originalmente publicado em 1973).

Lacan, J. (2007). O seminário, livro 23: o sintoma. Rio de Janeiro, RJ: Jorge Zahar. (Originalmente publicado em 1975-1976).

Miller, J. A. (2010). Extimidad: Los cursos psicoanalíticos de JacquesAlain Miller. Buenos Aires: Argentina: Paidós.

Miller, J. A. (2011). Perspectivas dos escritos e outros escritos de 
Lacan: Entre desejo e gozo. Rio de Janeiro, RJ: Zahar.

Miller, J. A. (2015). Mèrefemme. La Cause Du Désir: Revue de psychanalyse, 89, 115-122.

Solano-Suarez, E. (2015). SOS hombres maltratados. [Texto preparatório para o PIPOL7 - 30 Congrés européean de psychanalyse]. Recuperado

http://www.pipolnews.eu/es/eurocompas-lacanien-es/sos-

hombres-maltratados-por-esthela-solano-suarez/

\title{
Endereço para correspondência \\ Sérgio Laia
}

Universidade FUMEC (Fundação Mineira de Educação e Cultura)

Rua Cobre, 200, Cruzeiro, CEP 30310-190, Belo Horizonte - MG, Brasil

Endereço eletrônico: slaia@fumec.br

Heloisa Caldas

Universidade do Estado do Rio de Janeiro

Rua São Francisco Xavier, 524, $10^{\circ}$ andar bloco B sala 10024, Maracanã, CEP 20550-011, Rio de Janeiro - RJ, Brasil

Endereço eletrônico: helocaldas@terra.com.br

Recebido em: 16/08/2015

Aceito para publicação em: 25/08/2016

\begin{abstract}
Notas
${ }^{1}$ Em outro ponto de seu ensino, Lacan volta a insistir nessa dimensão estrangeira que mantemos com nossos corpos, porque em vez de dizer e de experimentar que "somos corpo", lidamos com nossos corpos como se fossem objetos que julgamos possuir - por isso, falamos "meu corpo", tal como "minha caneta", "meu carro", etc. (Lacan, 1979/2007, p. 561).

2 O termo surgiu a partir do movimento feminista quando Diana Russel utilizou-o publicamente em 1976 no Primeiro Tribunal Internacional dos Crimes contra as Mulheres e o definiu, em seguida, como "o assassinato de mulheres pelo fato de serem mulheres".

${ }^{3}$ No Brasil, dados do dossiê Mulher de 2014, lançado recentemente, pelo Instituto de Segurança Pública, revelam que, no ano passado houve um aumento de $20,67 \%$ nos casos de assassinatos, em relação a 2012. Em 2013, foram mortas 356 mulheres no estado do Rio de Janeiro - 52 delas atacadas por ex-maridos. O Globo de 27 de agosto de 2014. Na Argentina, uma mulher é assassinada a cada 30 horas. Foram 295 crimes no ano passado; dentre 46 deles o assassino era um homem submetido à medida de prevenção que o impedia de se aproximar da mulher. O diário La Nación de 7 de março de 2014.

* Professor Titular IV do Mestrado de Estudos Culturais Contemporâneos e do Curso de Psicologia da Universidade FUMEC (Fundação Mineira de Educação e Cultura); Pesquisador com projeto aprovado pelo Conselho Nacional de Desenvolvimento Científico e Tecnológico (CNPq) e pelo Programa de Pesquisa e Iniciação Científica (ProPIC) da Universidade FUMEC; Mestre em Filosofia e Doutor em Letras pela Universidade Federal de Minas Gerais (UFMG); Psicanalista, Analista Membro da Escola (AME), pela Escola Brasileira de Psicanálise (EBP) e Membro da Associação Mundial de Psicanálise (AMP).

** Professora Adjunta do Instituto de Psicologia da Universidade Estadual do Rio de Janeiro (UERJ); Docente do Programa de Pós-Graduação em Psicanálise da UERJ;
\end{abstract}


Doutora em Psicologia pela UFRJ (Universidade Federal do Rio de Janeiro); Psicanalista, Analista Membro da Escola (AME), pela Escola Brasileira de Psicanálise (EBP) e Membro da Associação Mundial de Psicanálise (AMP). 